JAKUB BUGAJSKI ${ }^{1}$

\title{
IS EVERY SINGLE HUMAN BEING A PERSON? A DISPUTE BETWEEN ROBERT SPAEMANN AND PETER SINGER
}

\begin{abstract}
One of the central issues of contemporary philosophy concerns the definition of the person. Many philosophers and bioethicists have sought to determine the basis for ascribing personhood, and to resolve the associated question of whether only human beings may be properly granted this status. Two contemporary thinkers have played a leading role in this debate, namely Robert Spaemann and Peter Singer. The former, coming from the tradition of Christian thought, seeks to demonstrate that the personality of a human being begins when he or she is conceived and ends with his or her death. In his opinion, only God, as the source of all life, has a right to exercise authority over human destiny. The opposite position is defended by the Australian philosopher Peter Singer. His philosophical views have emerged from the tradition of empiricist thought initiated by Democritus and expanded on later, above all, by John Locke. Singer postulates a descriptive theoretical account of persons, claiming that personhood results from the possession of a set of qualitative features, namely: to become a person, a human being ought to have certain properties, such as self-awareness, rationality of thought, or the possession of preferences - without these, he would say, one cannot even talk about persons. This paper seeks to confront the tenets of personalist ethics (as in Spaemann) with those of preference-based utilitarianism (Peter Singer), presenting the metaphysical, ontological and cognitive commitments that make up these two positions, but also asking whether there is any shared set of underlying concerns that could furnish a basis for dialogue between them.
\end{abstract}

Key words: personalism, utilitarianism, personhood, preferences, dignity

\footnotetext{
${ }^{1}$ MA; Jagiellonian University in Kraków; jakub.bugajski@doctoral.uj.edu.pl.
} 


\section{INTRODUCTION}

The aim of this article is to explore two contrasting philosophical approaches to the problem of the significance of persons: on the one hand personalism (as represented by Robert Spaemann), on the other what is known as utilitarianism of preferences (represented by Peter Singer). The focus will be on showing how the above-mentioned philosophers construe the problem of man's status as a person, where this issue, together with the question of how the term "person" should itself be understood, has proved central to contemporary debates in bioethics. We may first note that the foundations of contemporary personalism lie in a conception of human thought that first emerged in the context of the Boethian and Thomistic traditions: mankind is viewed there as somehow linked to the Absolute, as the source of all life. It is through Him that every human being, at his or her moment of coming to life, receives the substantial form that determines their status as a person, and this is why the human being is regarded as being identical with the person. Preference-based utilitarianism, meanwhile, stemming from the empiricist tradition of thinkers such as Locke and Hume, adopts a quite different attitude. Here the body is viewed mechanistically, and the status of personhood is only acquired after certain corresponding qualitative characteristics, such as rationality, self-awareness or the possession of preferences, have been suitably disclosed. Each and every being embodying the features just mentioned will, according to proponents of this utilitarianism, qualify as a member of the class of persons. The latter class somehow then constitutes an ontologically significant commitment to the existence of a certain species or kind, to be entertained in terms that involve specific metaphysical assumptions. Moreover, such a class may include not only members of the species Homo sapiens, but also instances of any other species of animal that happens to possess some of the above-mentioned features.

In its founding precepts, Western ethical civilization has frequently invoked the principle of the sanctity of life, which enjoins us to care for all beings belonging to the human family. Revisionist positions, however, such as that which we encounter in the philosophy of Singer, seek to deny this, appealing instead to the principle of equal consideration of interests and economic calculation. Thus, Singer would like to install a new ethic, based on the golden rule of utilitarianism namely, that we should maximise happiness and minimise suffering. The issue of the person then takes on 
a special significance, specifically in the context of the problematization of the principle of the sanctity of life. Should the latter then be undermined, the door will be opened to greater freedom in regard to abortion and euthanasia, while also permitting a significant liberalization of the laws pertaining to non-persons.

\section{IS THERE SCOPE FOR COMPARING METAPHYSICAL AND EMPIRICAL ARGUMENTS?}

The ideas of Spaemann and Singer rest on very different metaphysical foundations. The former issues from certain very strong theistic premises that play an organising role with respect to the entirety of God's normative system. Starting from the premise that God is the giver of life, Spaemann tries to base all of his thinking on a close relationship to the Christian philosophical tradition. In this context, the absolute, as the source of all existence, is seen as responsible for constituting the structure of the human being in terms that are essentially dualistic. According to the Thomistic tradition, the God-given soul is the component of the human being that defines its ontological status as a person. This particular sort of metaphysical construal of the structure involved then entails a well-defined ontology, as well as a cognitive and normative sphere pertaining to the person as such. Singer, on the other hand, takes a completely different approach to this issue, criticising as he does all theistic assumptions and drastically reducing the whole structure of metaphysics and ontology to a bare minimum. The fundamental point of departure here is certainly not some conception of the Absolute as the source of all existence, but rather assumptions based around the biological development of human beings. In the absence of the relevant empirically disclosed properties, no human (or other animal) can be considered a candidate for counting as a person. Only when such qualities as rationality, self-consciousness, or the possession of preferences have actually appeared may the being in question be determined to be one.

Hence, it is clear that what differentiates the two positions here is largely a matter of the metaphysical and ontological assumptions in play. The question which then arises is the following: is it possible to find some common ground that would allow these two quite different approaches to be meaningfully compared? As was already mentioned, Spaemann embraces a very strong ontological assumption, to the effect that every human 
being is a person, regardless of his dispositions and properties. To take on board what Spaemann is proposing, we must accept without question the particular ontological status that personhood comes to possess in the light of the metaphysical assumption that every human being is created in the image and likeness of God. Singer's vision of a person, on the other hand, focuses exclusively on properties that are strictly empirical and denies any relation to the Absolute. ${ }^{2}$

What underpins the conflict here, then, is that one of these lines of argument operates at the level of sharply defined a priori ontological commitments, the other at one where temporally specific, shifting and gradeable properties show up as significant, such as those pertaining specifically to the biological nature of man. Although in embracing either of these two assumptions one can talk about the personal status of man, in each case this will have to take on a radically different form. Moreover, as the author of this article believes, there in fact seems to be no way to straightforwardly level the playing field when it comes to comparing and cross-referencing metaphysical and ontological arguments with those which are empirical.

Interestingly, though, Spaemann, in his work, does try to explicate the relevant metaphysical-ontological structure in purely empirical terms, referring to the idea that this is a feature of all members of the human family, invoking the occurrence of propositional acts, and proffering an explanatory account of the status of personhood that appeals to the analysis of facts pertaining to how we use language. All of these points would seem to open up the possibility of engaging in a discussion with Singer at the level of issues of an empirical sort. Yet the fact remains that where Spaemann is concerned, even if the argumentation takes a form that is more empirical than metaphysical, it is still conducted from a point of view reflecting assumptions about the ontological status of persons. Beyond this, it is hard to see any viable basis for comparing the visions of Spaemann and Singer. At the end of the day, Spaemann's according of axiomatic significance to the status of the human being qua person is, as it were, simply closed to all further discussion. The point here is not that we should, on this basis, embrace some sort of presumption to the effect that Spaemann is approaching the matter on the wrong level. What this shows, rather, is that relations holding between assumptions associated with metaphysics

\footnotetext{
2 P. Singer, Practical Ethics, Cambridge 1999, p. 17.
} 
and with empiricism, even when taken together, fail to furnish a meaningful platform for comparing the competing arguments that surround the status of the person.

Singer, in his thinking about and conception of persons, focuses on quite different issues than Spaemann. In this regard, it will be useful to characterise his philosophical approach in terms of three essential features. Firstly, it is revisionist, seeking as it does to bring about radical change in respect of existing attitudes (especially in the Western world), where the latter are taken to largely manifest Christian ethical principles. The second feature to be noted here stems directly from this, and consists of his offering descriptions of certain specific phenomena (as in such works as Rethinking Life and Death: The Collapse of Our Traditional Ethics (Singer 1997) and Animal Liberation (Singer 2004)). The third is his attempt to replace the Western tradition of ethics in its entirety with a quite new and distinct model. ${ }^{3}$ These features are revealing of Singer's motives, especially as regards his project of creating a philosophy of persons resting exclusively on empirically disclosed properties: for him, such an approach marks an adaptation that is called for as a response to the newly emerging demands placed on bioethics - demands that correspond to problems that personalism and its underlying attitudes can no longer adequately address. Thus, Singer proposes a move away from the metaphysical assumptions and principles pertaining to the sanctity of human life, to a focus on the development of the biological and psychological structures observable in human beings instead. ${ }^{4}$

\section{THE BIOETHICAL CONSEQUENCES}

In the philosophies of both Singer and Spaemann, the value that above all serves to establish the status of a human being qua person is that which we find expressed in the concept of dignity. Singer construes the moral sphere as just what is entailed in the way of consequences flowing from naturalistic assumptions - assumptions, that is, of the sort that seek to

${ }^{3} \mathrm{~W}$. Bołoz, On the need to engage with utilitarianism in bioethics, in: W. Bołoz, G. Höver (eds.), Utilitarianism in Bioethics, Warsaw 2002, p. 18.

${ }^{4}$ P. Singer, Rethinking Life and Death: The Collapse of Our Traditional Ethics, New York 1997, p. 111. 
entirely reduce human nature to its natural biological conditions and also rule out any appeals to religiously founded lines or modes of argument. Concomitantly with this, he regards any putative instantiation of objective value as wholly unacceptable, so that his overall approach raises wider questions about matters metaphysical and empirical, as well as issues specifically concerned with human dignity. ${ }^{5}$ Spaemann, by contrast, in invoking religion as a point of reference, proposes an absolute form of axiology - one that permits him to posit the value expressed in the concept of dignity as being part and parcel of the objective structure that defines membership of the human species itself.

The question of whether the foetus can be considered an entity possessing the status of a person is the most controversial point in discussions relating to the philosophy of personhood. Singer believes that the interests of all suffering beings - where suffering itself is taken to be a feature specific to consciousness - should be taken into account, so that persons with an intellectual disability or affected by senile dementia should not be excluded from our society. He also argues that, on the basis of such an appeal to suffering, the foetus itself should be protected from the third trimester of pregnancy on (i.e. from the time of the onset of the nociceptive system), since its interests at that stage should already be considered to furnish what essentially matters about suffering. This, however, prompts the question of exactly how one is to determine which foetuses do or do not count as having a sufficiently developed nociceptive system for such purposes.

There is a genuine problem here - one that may be said to constitute the real focus of the thinking of both Spaemann and Singer. Any creatures classifiable as Homo sapiens must, one might think, also have the status of conscious beings; yet, prior to the third trimester of pregnancy, this feature will not actually hold for the human foetus itself. Singer's position on this issue is very clear: if the being does not feel suffering, its interests need not be taken into account in any event. The personalist stance as represented by Spaemann, on the other hand, is precisely to argue that the foetus counts as a being possessing the status of a person throughout the duration of its development cycle. According to Tadeusz Biesaga, the criteria invoked when seeking to determine the status of the foetus in this

\footnotetext{
${ }^{5}$ W. Bołoz, On the need ..., p. 20.
} 
regard fall into two distinct classes: firstly, those that recognise the foetus as a person from the very beginning (Spaemann); secondly, those that ascribe significance to some particular point in the course of the biological development of the human being (Singer). Amongst the former we may reasonably include criteria based on the facts connected with fertilization (e.g. involving triggering of the male and female gametes), with genetics (where what results from conception is taken to already reflect properties unique to the human species), or with the continuity of human development over the entire course of the prenatal period. ${ }^{6}$

Of course, these are just the kind of arguments Singer would seek to reject. His main point would be that the criteria described above relate to the human species as a reproducible type, and not to the person construed as anything more than this. He posits a class of people that is somehow beyond all biological species. For him, criteria based on the sheer fact of fertilization or on genetics will only pertain to a human being at a stage where he or she fails the test for classificatory inclusion into the set of all beings recognised as persons. Any criterion related to the continuity of development of the foetus in the prenatal period would also be problematic for Singer. This is partly because of the fact that such arguments are associated to some degree with, what we may briefly describe, as the potentiality of the human being for developing person-related properties. At the same time, though, above and beyond Singer's own arguments in connection with this issue, it is open to him to pose the following question: what happens in the event that the continuity of development of the foetus is itself not realised? Moreover, linked to this is yet another question, which concerns why we should care about some purported essence connected with the possession or non-possession of preferences, or even with the experiencing or non-experiencing of suffering. Here, we see reflected, in a quite special way, the rather hyperbolic character of the metaphysicalontological concerns brought into play: somehow, it is assumed, the status of a being counting as a person should be assignable to each and every human. According to the fertilization criterion, for instance, there would have to be a specific moment involving a merger of male and female gametes, at which point something is brought to life that contains within itself the embryo of a God-given human soul (among philosophers and theologians

${ }^{6}$ T. Biesaga, The Anthropological Status of the Human Embryo, in: T. Biesaga (ed.), Foundations and Applications of Bioethics, Cracow 2001, p. 101. 
there is an ongoing dispute about the moment of animation, in the sense of the point in time from which the embryo "is" the soul of a human, and thus has the status of a person). However, for Singer, those who embrace such metaphysical assumptions while failing to be explicit about the need to recognise any such moment merit criticism, on the grounds that all the while the creature does not actually instantiate the requisite properties, it cannot be accorded the status of a person.

The second approach to taking the foetus to constitute a person involves what have come to be known as "late" criteria - these being those invoked to determine the status of a creature making a transition between certain currently instantiated states or properties and others. This group may include such criteria as the following: (a) that a zygote has been formed (twenty-one hours after fertilization), (b) that implantation has occurred (fourteen days after fertilization), (c) development of the nervous system (forty days after fertilization), (d) presence of a capacity for independent functioning, (e) the occurrence of birth, ( $f$ ) conscious reception of stimuli from the surrounding reality, (g) the fact of a life's having been conceived by parents (taken as marking their acceptance of it), and (h) the social and material circumstances of the embryo (likewise taken as marking some form of acceptance of its status in this regard). ${ }^{7}$ However, Spaemann would certainly object that such considerations are bound to fail as criteria, as they do not recognise the inherent value of the human nature possessed by every single person right from the moment of conception through to their natural death. Singer, on the other hand, would be open to most of these, though he would probably dismiss the first one. (Others, we may suppose, he would accept, providing they are made conditional on the fact of suffering.) Thus, it is clear that strong assumptions - metaphysical in the case of Spaemann, empirical for Singer - give rise to radically different approaches to bioethical issues, in particular where the human foetus is concerned. These, in turn, offer no real basis for thinking that widely divergent attitudes on such matters as abortion could be reconciled simply by an appeal to certain ideas about the status of the embryo or the moment of a creature's coming into life. Differences in the basic assumptions involved give rise, then, to differences about cognitive issues, and consequently also about normative and/or ethical matters.

\footnotetext{
${ }^{7}$ T. Biesaga, The Antrhropological . .., p. 102.
} 


\section{A DIFFERENT MEANING OF "DIGNITY"}

Opponents of recognising the inherent dignity of the human being very often distinguish between the fact of its existence in the form of an embryo (or, later, a foetus) and that of its existence as a true essence, where the latter is taken to require that it has already developed the appropriate cluster of empirically observable properties. ${ }^{8} \mathrm{~A}$ much-raised objection is that even if a child does not have the same powers as grown-ups, this does not mean that he or she should be denied the right to life. The latter relies on very different assumptions than do the more mundane everyday social rights associated with adult humans. Hence, we can in fact distinguish four concepts of human dignity, each of which refers in a somewhat different way to the realm of collective human affairs. The first, ontological dignity, is ascribable to every viable instance of human existence and human nature. (This, I suspect, will prove to be the concept of dignity most relevant to the problem of personhood). The second of these is the dignity of the conscious, which accrues to a conscious entity only with the onset of those particular tendencies or features uniquely associated with consciousness. A third concept of dignity is acquired dignity, which comes into play once the right to possess characteristics associated with beings qua persons has been acknowledged. Fourthly and finally, there is relational dignity, which conveys respect for the other person, for society, or for the Absolute. ${ }^{9}$ Contemporary reflections on human dignity have, it is fair to say, mainly focused on the first and second of these four notions. We see the first clearly manifested in the metaphysico-ontological axiom that, as was mentioned earlier, is the focus of Singer's attack, and which furnishes the basis for the personalist approach itself. In contrast, Singer's own philosophy clearly rides on the back of a conception of this that is centred on the dignity of the conscious, from which it would follow that human dignity is only attained with the arrival at a state of possession of certain properties.

Turning to the field of applied medical practice, we find that what follows from the tenets of the personalist philosophical approach turns out to be highly restrictive. At first glance, what we encounter is something

${ }^{8}$ P. Singer, Practical ..., p. 99.

${ }^{9}$ T. Biesaga, "The right to live and other powers", Life and Fertility, vol. 6, no. 18 (2012), p. 77. 
founded on the principles of the sanctity of life and dignity, with the latter conceived in the context of a specifically Christian ethics, where this offers protection to all persons belonging to the human species. As has already been noted, for personalism, life begins with the conception of the individual. Its evolution in the womb, adaptation, and subsequent development, only serve to highlight changes to an underlying biological disposition, relative to which the status of a person counts as already in place. From this it would follow that abortion, carried out at any stage of foetal development, would constitute the destruction or murder of a person (in a sense of the latter term that would be construed as applicable to all members of the species Homo sapiens), and this, in turn, is tantamount to a denial of the possibility of ever excluding such a living being from the normative sphere of moral concern that helps to sustain human society. Viewed from the standpoint of Christian personalism, then, abortion amounts to an act of social exclusion and (at least from a religious perspective) counts as a sin, since it involves obliterating from this world the potential future life of a being qua person. Of course, it may be asserted that features such as the possession of preferences or rationality will themselves only exist then in a state of potency, but viewed in these terms the fact remains that in depriving the person of their life, the overarching value at stake - expressed in the concept of dignity - has not been respected. Seen thus, we may say that abortion eliminates the continuity of personal life and, in so doing, denies its full realization.

The tenets of preference utilitarianism, as presented by Singer, leave room for significantly more freedom in respect of moral and ethical issues. Indeed, his philosophy of personhood is open to being constantly updated and modified, with the consequence that the entity in question may, in theory, at various times gain or lose the status of being a person. This approach allows for a wide range of options where forms of practical medical intervention or treatment, and their associated moral choices, are concerned. Still, a common argument against Singer's position comes from the thought that beings continue to exist when they are in a nonconscious state, even though - as Locke noted - a person when asleep actually loses most of the characteristics which, for Singer, would be constitutive of their being a person. Singer's response to this objection is to insist that just one single declaration of preference stemming from the life of a person is sufficient to enforce upon us an obligation not to kill where that entity is concerned. The implication here is that a person, in exhibiting 
self-awareness and the possibility of showing preferences, already declares a willingness for further existence. A highly interesting further contribution to this debate has been made by Derek Parfit, who holds that what constitutes a being qua person is something he calls the Relation $\mathbf{R}$. This he defines in terms of the "psychological interconnectedness and/or continuity of the mental, brought about by the right kind of causal factors". ${ }^{10}$ In other words, he claims that what ultimately determines personhood is the type of connection - in this instance a causal linkage - obtained between our thoughts. What is striking is that while such a theory may, in certain respects, be adduced in defence of Singer's position, it nevertheless also seems to put in question the latter's thesis concerning the role of self-awareness vis à vis personhood.

Utilitarianism of preferences cannot be interpreted so as to furnish strict legal and moral rules, perhaps because it does not have strong metaphysical assumptions, such as would imply an unchanging attitude to reality. Hence, abortion, construed as the elimination of a live foetus that nevertheless does not qualify as a person, is not seen as in any way morally problematic. Moreover, it does not imply any corresponding exclusion of the foetus from the structures of social life, as if the foetus not satisfying the relevant empirical characteristics demanded by personhood could somehow itself be translated into the more obviously normative terms of these structures of society. We may therefore conclude that utilitarianism does not take the position that condemns abortion as a form of social exclusion. That would involve the elimination of people, whereas in this case the entities being excluded simply do not belong to any such group.

The principal challenge posed for practical morality by any sort of ethical relativism concerns the shifting status attached to the dignity of the person. This issue is primarily considered with reference to the doctor-patient relationship, where what is at stake is how, exactly, we might wish to see the patient construed as a person. ${ }^{11}$ This connects up directly with the "feminist argument" introduced by Singer in his book Practical Ethics, where he states that the foetus counts as a part of the body of the woman, who in turn is free to decide about its removal. ${ }^{12}$ In this case, then,

${ }^{10}$ D. Parfit, Reasons and Persons, Warsaw 1984, p. 258.

${ }^{11}$ T. Biesaga, Autonomy and human dignity, in: G. Hołub, P. Duchliński, T. Biesaga (eds.), From Autonomy of Persons to Autonomy of Patients, Cracow 2013, p. 169.

${ }^{12}$ P. Singer, Practical . ... p. 145. 
the idea of dignity has been, so to speak, "subtracted" from the moral equation, and replaced by a radical notion of autonomy. We leave it to the woman herself to decide about terminating "her" pregnancy, bypassing the supposedly objective moral order that, according the personalist, should be acknowledged as shaping our reality.

If this is so, then the really fundamental issue being contested here between utilitarian and personalist philosophers concerns the concept of human nature. The former construe it as a set of empirical characteristics, on the basis of which the concept of a person can then be constructed. With such a classification we are, from an ethical point of view, able to "institute" a new kind or species, which by virtue of certain biological properties can achieve a status that is such that its form, corresponding to ascriptions of the status of a person, counts as disclosing an independent and distinct metaphysical norm - one by no means necessarily limited to the species Homo sapiens. Singer here relies heavily on biological and sociological accounts of the evolutionary and/or developmental steps that must be achieved if an entity is to be judged capable of producing the kind of feature set that would merit attributing to it the status of a person. ${ }^{13}$

Utilitarianism of preferences is generally assumed to be radically impervious to all forms of religious grounding. It lacks the restrictive assumptions of ontological personalism, and is focused instead on empirical experience. Utilitarians, such as Singer, do not normally accept the existence of God, and so are inclined to dismiss any tenets that imply an appeal to God as the foundation-stone for the existence of morality. The dignity of the person is thus no longer regarded as an a priori abstraction based on some kind of substantial form, something which, according to utilitarians, does not exist anyway. Man is seen instead as being subject to an evolving set of constitutive conditions made up exclusively of empirically disclosed characteristics. Neither his biological functions nor his spiritual dimension (by which I mean any psychological structures pertaining to human beings) determine membership of the class of persons. This contrasts with personalism, which, as was noted earlier, straightforwardly identifies the concepts "human" and "person" with one another, with the implication that in our dealings with any given human being we should always strive to view them through the prism of the person they are (as exemplified in Kant's

${ }^{13}$ J. Synowiec, Human Nature in Peter Singer's Philosophy, in: P. Duchliński, G. Hołub (eds.), Faces of Human Nature, Cracow 2010, p. 234. 
injunction to "Conduct yourself in such a way that you treat humanity, whether in your own person or in the person of any other, never merely as a means to an end, but always also as an end"14). The anthropology underpinning utilitarianism would certainly not endorse any such classification, though. Singer demands to know why it is that we are expected to presume that every being belonging to the species Homo sapiens will qualify as a person. Utilitarianism thus rejects any dogmatic view of reality, be it couched in anthropological or in ethical terms, and tries instead to define the set of all persons on the basis of experience alone. Indeed, such an approach was pursued earlier by Locke, an opponent of Christian thought, when he argued that the memory of the individual should be considered the determinant of whether a human being is a person or not. It was on that basis that he felt able to assert that every person, even when just drunk, ceases to be a person for a time, becoming one once again only when they have fully recovered their capacity for mental functioning.

We can therefore see that personalism views what it means to be a person as some sort of whole: a unity of the spiritual with the corporeal which, in any case, cannot be separated from each other. This creates an objective moral order, implying ethical and legal restrictions that are binding in their force. What is controversial, though, is that the Christian philosophy invoked here, with its strongly defined metaphysical basis, does not appear to allow for any element of ethical relativity to be introduced at all. Each and every being embedded in the structure posited by ethical personalism will therefore exhibit exactly the same features: it will be irreplaceable, and will possess a status that cannot be compromised. This is what determines the continuity of its existence as something originating with fertilization and terminating with brain-stem death, and on this basis we can see that any attempt to intervene in or interfere with the personal sphere of a human being is bound to run counter to the dignity and inviolability of the person they essentially are..$^{15}$

Personalist approaches to ethics, we may note, largely rest on Christian anthropology and ontology. Indeed, to separate out these two aspects seems well-nigh impossible, as the basis for both is Thomistic philosophy, which engendered each of them. God is here counted the source of all of the values ascribable to a being qua person. Thanks to Him every

${ }^{14}$ I. Kant, Groundwork of the Metaphysic of Morals, Warsaw 2013, p. 62.

${ }^{15} \mathrm{~J}$. Crosby, Sketch of a Philosophy of the Person, Cracow 2007, pp. 55-56. 
personal being has dignity, which is included in the set of values deemed non-negotiable, permanent, and predicable of humankind a priori. Dignity, moreover, institutes a relation between the person and God: it is a kind of transcendent feature, by virtue of which a human being acquires the status of being a person.

At the very centre of ethical personalism lies the notion of a person who, as a substantial being, consists of a substantial form - there being, in every human being, a soul - along with its material correlate, so that what is constituted from this is the human being as a whole. The soul is rooted in God, the Creator of all reality. The consequence of such a model is that every human being has a soul, received from God. Why? Because every human being, without exception, has a substantial form. Such a direct relation between the human soul and God implies the existence of dignity as a non-transferable and universal value, and if every person is created in the image and likeness of the Absolute, then this will be an overarching feature embodied in the hierarchy of material beings. Even if we are also dealing here with the classification of some sort of empirically disclosed set of elements, the fact remains that the issue is addressed at the level of metaphysics. We can only conceive of the overall ethical reality in which the person is granted its special place here on the basis of such a priori commitments. What this means is that, as was said before, the whole anthropological ethics of personalism is really just a matter of ontology, and is tantamount to writing an equals sign between the human being and the person.

\section{BIBLIOGRAPHY}

Anzenbacher A., Christliche Sozialethik: Einführung und Prinzipien, Paderborn 2010.

Biesaga T. (ed.), Foundations and Applications of Bioethics, Cracow 2001.

Biesaga T., "The right to live and other powers", Life and Fertility, vol. 6, no. 18 (2012).

Boethius, Theological tractates, Kęty 2001.

Bołoz W., Höver G. (eds.), Utilitarianism in Bioethics, Warsaw 2002.

Crosby J., Sketch of a Philosophy of the Person, Cracow 2007.

Duchliński P., Hołub G. (eds.), Faces of Human Nature, Cracow 2010.

Frankfurt H., "Freedom of the Will and the Concept of a Person", The Journal of Philosophy, vol. 68, no. 1 (14 January 1971).

Hołub G., Duchliński P., Biesaga T. (eds.), From Autonomy of Persons to Autonomy of Patients, Cracow 2013. 
Kant I., Groundwork of the Metaphysic of Morals, Warsaw 2013.

Locke J., An Essay concerning Human Understanding (part I), London 1824.

Parfit D., Reasons and Persons, Warsaw 1984.

Sidgwick H., The Methods of Ethics, Cambridge 2007.

Singer P., Rethinking Life and Death: The Collapse of Our Traditional Ethics, New York 1997.

Singer P., Practical Ethics, Cambridge 1999.

Singer P., Animal Liberation: The Definitive Classic of the Animal Movement, New York 2004.

Singer P., The Life You Can Save, New York 2009.

Smith Ch., What is a Person?: Rethinking Humanity, Social Life, and the Moral Good From the Person Up, Chicago 2010.

Spaemann R., Persons. On the Difference between Something and Someone, Warsaw 2001.

Spaemann R., Boundaries, Warsaw 2006.

Stephens W., The Person: Readings in Human Nature, New York 2006.

Steven L., The Category of the Person: Anthropology, Philosophy, History, Cambridge 1987. 